\title{
INTRA-OCULAR PRESSURE, GLAUCOMA, AND GLAUCOMA SUSPECTS IN A DEFINED POPULATION*
}

\author{
BY \\ F. C. HOLLOWS $\dagger$ AND P. A. GRAHAM \\ Epidemiological Research Unit and Department of Ophthalmology, Royal Infirmary, Cardiff
}

TOTAL population studies are the only certain way of gaining reliable information on the prevalence of insidious conditions like chronic simple glaucoma. The sine qua non of a total population study is exact knowledge of the composition of the population. In the Rhondda valley the Medical Research Council has laboriously carried out a census so that the exact number of persons and their age and sex are known for this area. Over the past 15 years the M.R.C. has earned the co-operation of this population by its efforts in detecting miners' pneumoconiosis, pulmonary tuberculosis, and other diseases. Such a situation was admirably suited for a total population study of the prevalence of glaucoma, and in the summer of 1963 the authors carried out such a study. To our knowledge the only previous similar study is that done by Strömberg (1962) at Skövde in Sweden.

The aims of our study were fourfold:

(1) Collection of reliable data on the distribution of intra-ocular pressure in an unselected population when measured with both indentation and applanation tonometers.

(2) Selection from this population of a group of persons who by conventional ophthalmological opinion were glaucoma suspects, so as to study these people and attempt a randomized trial of medical therapy.

(3) The detection of unknown cases of glaucoma and estimation of the true prevalence of glaucoma of all types.

(4) Tabulation of the extent of eye disease in an unselected population.

\section{(1) The Population}

\section{Methods of Survey}

Three villages were chosen as containing a population that was considered to be of manageable size. All were covered by the M.R.C. census. The age and sex composition of the population is shown in Table I (opposite).

In view of the difficulty of examining the very old, it was decided that persons above 75 years of age would not be examined. The lower limit was set at 40 years. There were 4,608 persons within these age limits, of whom we examined 4,231-91.9 per cent. The $8 \cdot 1$ per cent. who were not examined were interviewed and if they gave a history of treatment for eye disease details were sought at the medical centre involved. We feel that the coverage of this survey is adequate and better than most studies of this size. A team of professional

* Received for publication January 10, 1966

$\dagger$ Present address: Division of Ophthalmology, School of Surgery, University of New South Wales, Sydney, Australia 
TABLE I

Age and Sex Composition of Population (per cent.)

\begin{tabular}{c|c|c|c|c}
\hline \multirow{2}{*}{ Age Group (yrs) } & \multicolumn{2}{|c|}{ Ferndale } & \multicolumn{2}{c}{ England + Wales } \\
\cline { 2 - 3 } & Male & Female & Male & Female \\
\hline $40-44$ & $18 \cdot 0$ & $16 \cdot 5$ & $18 \cdot 2$ & $15 \cdot 2$ \\
$45-49$ & $16 \cdot 0$ & $16 \cdot 9$ & $17 \cdot 9$ & $16 \cdot 2$ \\
$50-54$ & $18 \cdot 2$ & $15 \cdot 8$ & $17 \cdot 9$ & $16 \cdot 5$ \\
$55-59$ & $16 \cdot 0$ & $15 \cdot 2$ & $16 \cdot 4$ & $15 \cdot 7$ \\
$60-64$ & $15 \cdot 0$ & $14 \cdot 8$ & $13 \cdot 0$ & 13.9 \\
$65-69$ & $10 \cdot 1$ & $11 \cdot 3$ & $9 \cdot 7$ & $11 \cdot 9$ \\
$70-74$ & $6 \cdot 7$ & $8 \cdot 5$ & $6 \cdot 9$ & $9 \cdot 6$ \\
\hline Mean Age (yrs) & $55 \cdot 1$ & $55 \cdot 6$ & $54 \cdot 7$ & $55 \cdot 9$ \\
\hline Males per 1,000 Females & 860 & & 881 & \\
\hline
\end{tabular}

field research assistants visited the entire population and made appointments for those willing to take part in the study. The maximum number seen on any day was 251 persons; the initial survey involved eight weeks of examinations.

(2) Details of Examination.-This was carried out in eight parts:

(i) Registration and interrogation.

(ii) Field examination using the Friedman multiple pattern type machine. This was done on every third patient to arrive at the clinic. This procedure was the most lengthy of those done and caused a bottle-neck in the flow of patients if more than one in three was attempted.

(iii) Instillation of fluorescein and local anaesthetic.

(iv) Slit-lamp examination of the anterior segment of each eye.

(v) Applanation tonometry - always right eye first.

(vi) Schiötz tonometry-always right eye first.

(vii) Ophthalmoscopy. Except where opacities in the media prevented it, all optic discs were examined.

(viii) Consultation and disposal. The ophthalmologist who was performing Schiötz tonometry and optic disc examinations informed each patient of the result of the tests and where necessary arranged for him to be seen again or referred for treatment or supervision.

\section{(3) Conditions of Tonometry}

Each ophthalmologist performed each method of tonometry on alternate days and measured very nearly the same number of patients with each instrument.

The same certified Schiötz and Goldmann tonometers were used for all measurements. We had earlier carried out tests on our reliability with both instruments. These tests resulted in our statistician formulating a convention for reading the instruments

We read all Schiötz readings to the nearest half-scale division below the indicated level when the mid-point of oscillation of the needle was not on a division mark.

We read the applanation instrument to the next whole millimetre below the indicated level when the drum was not coincident on a $2 \mathrm{~mm}$. mark. Our statistician devised a nomogram that defined the limits of acceptability of difference between readings of each method for the same eye. If the discrepancy between the two methods was in excess of 
these limits the patient was asked to return next day for a repeat of the dual tonometry when the observers had interchanged machines. We repeated 235 paired readings. We considered this built-in check a vital element in the veracity of our readings as frequently the repeat readings showed one or other method to be at fault on the first measurement.

\section{Results and Discussion INTRA-OCULAR PRESSURE}

Qualifications.-For the following tabulations we have (1) rejected all readings of glaucomatous eyes; (2) rejected all readings of eyes with diseases which affect tension; (3) never combined right and left eyes in the same tabulation.

\section{A. Applanation Pressure}

\section{(1) Distribution and Skewness}

Fig. 1 shows how applanation readings are distributed in 1,873 male left eyes; male right eyes and both female eyes are similarly distributed.

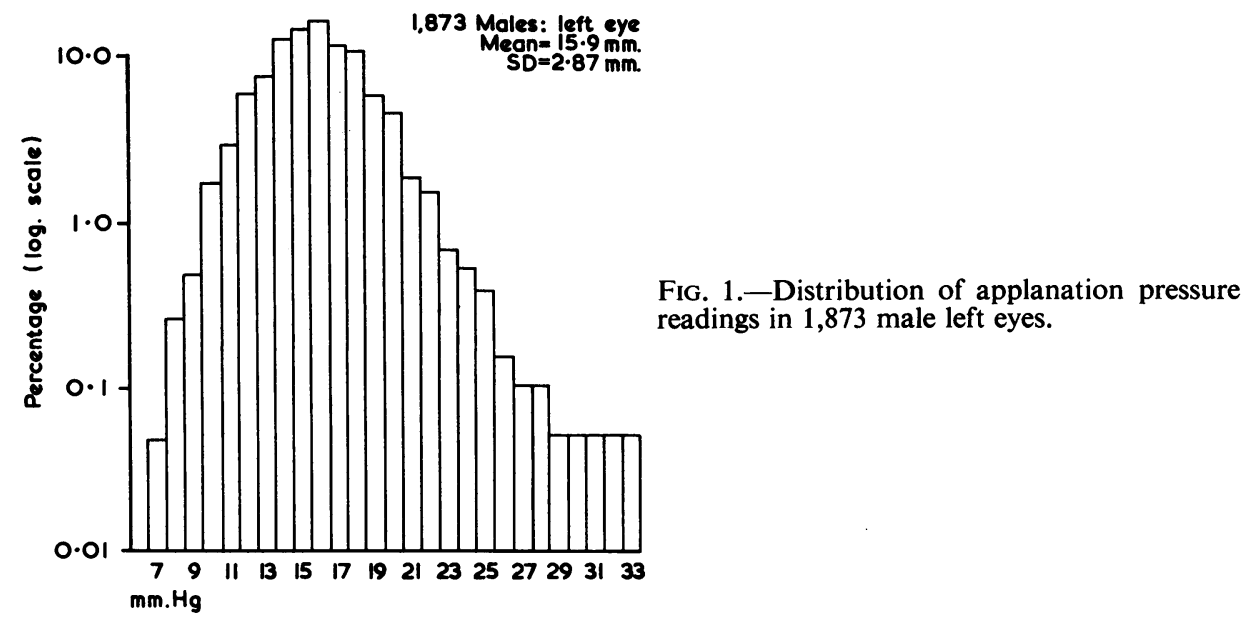

The histogram is on a log scale and shows skewness to the right so that the distribution is not Gaussian. Our statisticians, using a computer, have analysed this skewness to see if any one particular age group or sex is more involved than another. Fig. 2 (opposite) shows in graph and table form how the skew to the right, or the tendency for more readings to be higher than in a normal distribution, increases with age for male right eyes. Similar results occur for male left eyes and for female readings.

Armaly (1965) has recently shown somewhat similar results. Our ogives show that, up to 60 years, most readings fall on, or close to, the straight line of a normal distribution. At the 60-year level skewness increases and a greater number of readings are high and do not fall on the line of a normal distribution.

Tests for skewness were tabulated under g. increase for those aged 60 and above, and this change in skew is statistically significant as shown by the " $t$ " test.

It appears, then, that in the over-60s a larger proportion of the population has high pressures than in the under-60s, and this bears out Strömberg's conclusion of the timing of the onset of ocular hypertension. 


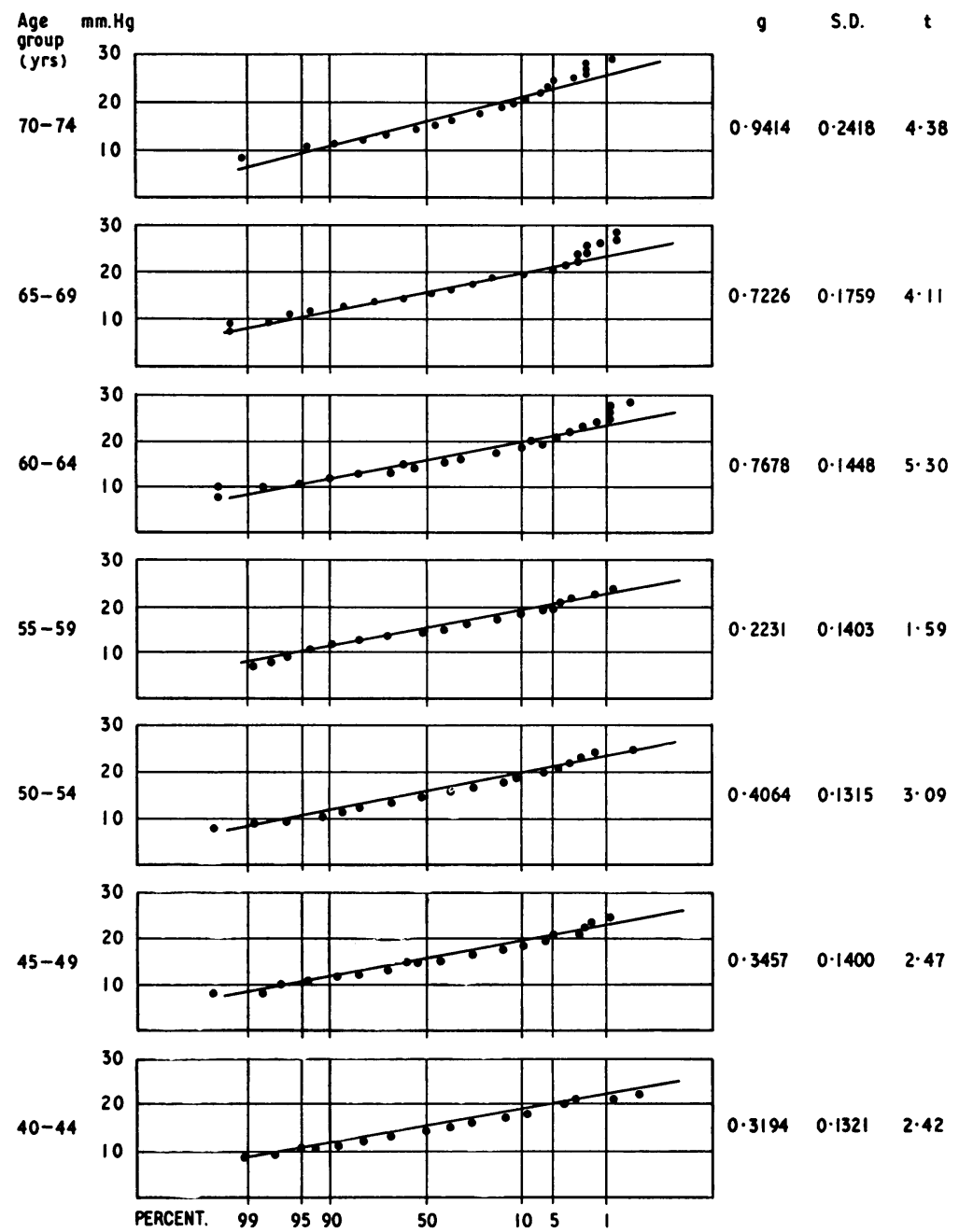

FIG. 2.-Readings in male right eyes, showing increased pressure with age.

\section{(2) Factors affecting Applanation Pressure}

(a) Age.-Applanation pressure increases with age (Fig. 3, overleaf), where the mean pressure for each 5-year age group from 40 to 75 years is plotted. An almost identical increase in age occurs in left eye readings. This rise with age is statistically significant.

(b) Sex.-Fig. 3 shows that for all except the 40-45-year age group women have higher applanation pressures than men. This difference, of the order of $1 \mathrm{~mm}$., is statistically significant and occurs in right and left eye readings.

(c) Time of Day.-We measured pressures in three sessions-morning, afternoon, and evening. As expected, there was a marked fall in mean pressures as the day advanced. In Fig. 4 (overleaf), mean morning pressure-mean evening pressure is plotted against age for male and female right eyes. Similar results occur for left eyes. 


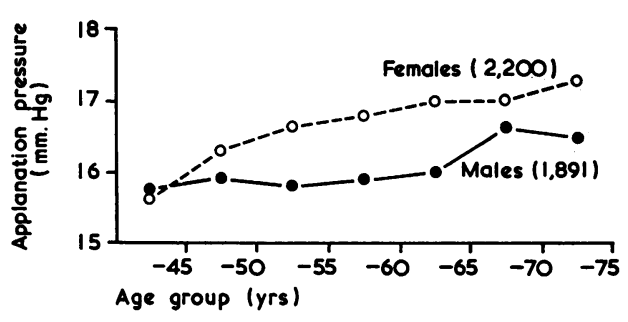

FIG. 3.-Applanation pressures in 2,200 female and 1,891 male right eyes, by age group.

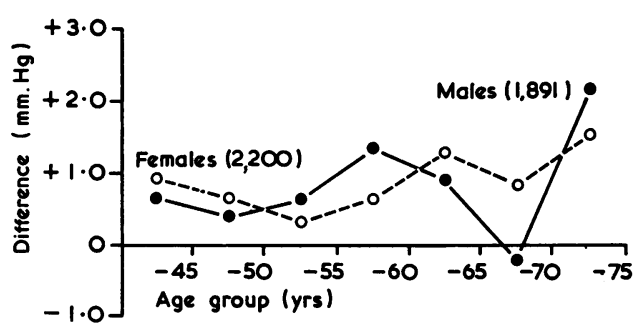

Fig. 4.-Difference in applanation pressure between morning and evening readings in 2,200 female and 1,891 male right eyes, by age group.

This effect is of the order of $1 \mathrm{~mm} . \mathrm{Hg}$ and is statistically significant.

A full statistical treatment of the effects of age, sex, and time of day on applanation pressure has been published elsewhere (Graham and Hollows, 1964).

(3) Error.-Two sources of error in the applanation pressure distributions are shown in our results.

(a) Digit preference.-In Fig. 1 it can be seen that there is a relative deficiency of odd-numbered readings. Digit preference, especially for even numbers and usually differing for each observer, occurs in most measurements but has received scant mention in the literature on glaucoma. In our hands the applanation tonometer was susceptible to this error for male right eyes as shown, and for male left eyes and both female eyes.

(b) The decision effect.-When an observer has to choose between normal and abnormal he is under pressure not to remain undecided about any cases. An intraocular pressure of $21 \mathrm{~mm}$. $\mathrm{Hg}$ is considered to be on the border between normality and abnormality. In Fig. 5 (opposite), the relative deficiency of $21 \mathrm{~mm}$. $\mathrm{Hg}$ readings could be due to this effect, which also occurs for female right eyes and for male right and left eyes. It is not inconceivable that this effect could considerably influence the result of case-finding tonometric surveys.

\section{B. Schiötz Pressure}

\section{(1) Distribution and Bimodality}

When we plot Schiötz pressures as proportions on log paper (Fig. 6, opposite) (female right eyes and both male eyes are similar) the distribution shows considerable bimodality. The valley in the distribution coincides with the change in tonometer weight necessary if readings below three scale divisions are to be avoided.

Readings of less than three scale divisions are better avoided as they fall on the steep part of the calibration curve and are liable to considerable error if conversion to $\mathrm{mm}$. $\mathrm{Hg}$ is attempted. Clearly, then, our Schiötz pressure readings are distributed bimodally, but this bimodality is an artefact. Schiötz pressures cannot conform to a normal distribution as higher readings need a different weight and do not form part of the same series of continuous variables. 


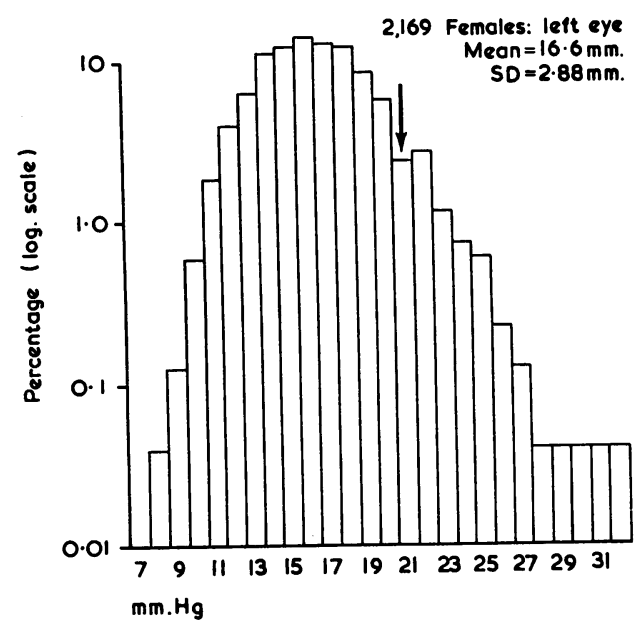

FIG. 5.-Percentage distribution of applanation pressure readings in 2,169 female left eyes, showing deficiency at $21 \mathrm{~mm}$. $\mathrm{Hg}$.

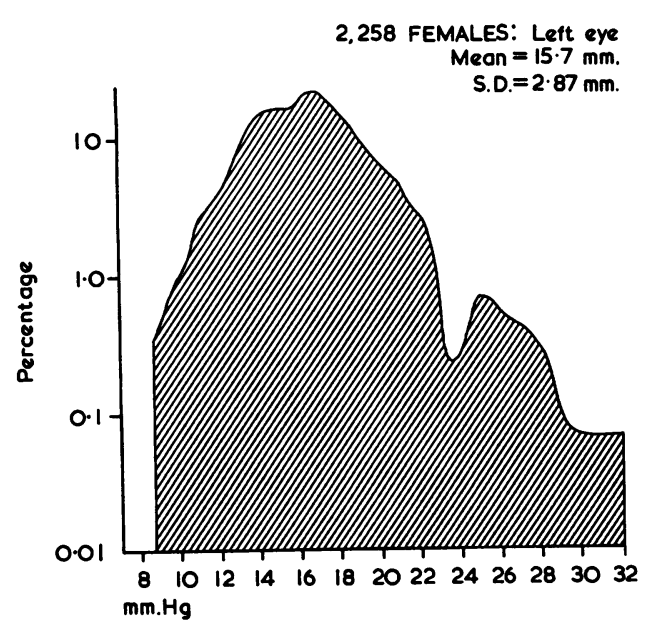

FIG. 6.-Schiötz pressures plotted as proportions on log. paper $(2,258$ female left eyes).

\section{(2) Factors affecting Schiötz Pressure}

(a) Age.-Fig. 7 shows a tendency for Schiötz pressures to increase with age in female right eyes, but not in male right eyes. Left eyes show the same trends. The increase in Schiötz pressure with age for females is statistically significant but is not so for males. It is likely that this result reflects the relative insensitivity of the Schiötz instrument, as males have less increase with age in applanation readings.

(b) Sex.-Fig. 7 shows a higher Schiötz pressure in female right eyes than in males. This is also the case for left eyes and is statistically significant.

(c) Time of Day.-The effect on Schiötz pressure is seen in Fig. 8. The fall in pressure as the day proceeds is similar to that in applanation pressure (of the order of $1 \mathrm{~mm} . \mathrm{Hg}$ ) and is statistically significant.

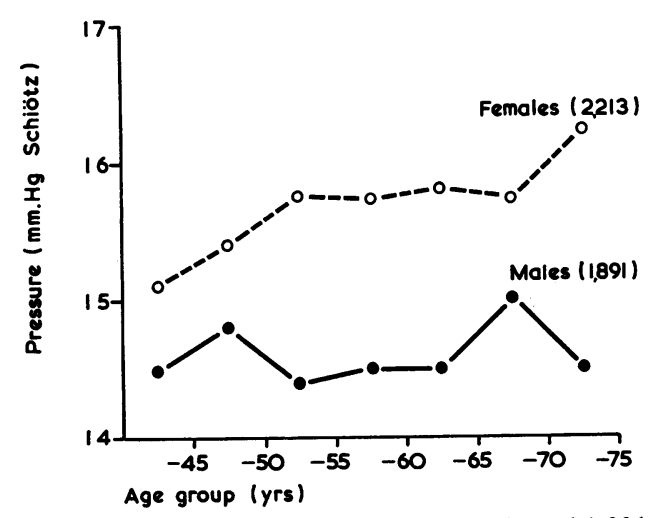

FIG. 7.-Schiötz pressures in 2,213 female and 1,891 male right eyes, by age group.

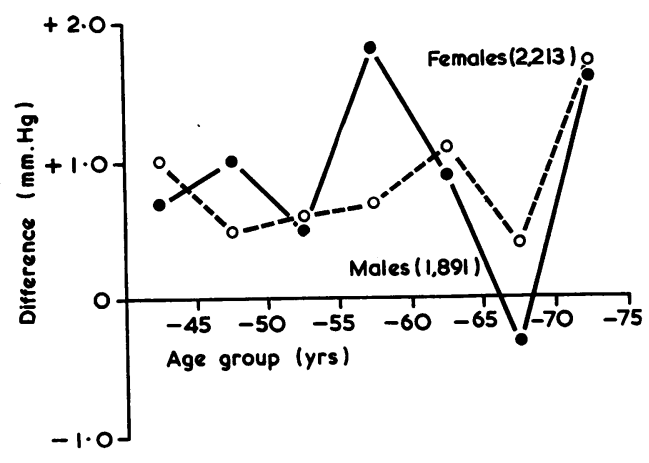

FIG. 8.-Difference in Schiötz pressures between morning and evening readings in 2,213 female and 1,891 male right eyes, by age group.

For the statistical treatment of these three effects on Schiötz pressures, see Graham and Hollows (1964). 


\section{(3) Error}

Digit preference and decision effect errors play an insignificant part in Schiötz pressure tabulations because the steps (half-scale divisions) are large and the range of usual readings is small.

\section{Meaning of Normal and Average Values}

Average values for intra-ocular pressure as we found them can be seen in Table II.

TABLE II

Normal Intra-Ocular Pressure (mm. Hg)

\begin{tabular}{c|c|c|c|c|c}
\hline \multirow{2}{*}{ Sex } & \multirow{2}{*}{ Eye } & \multicolumn{2}{|c|}{ Schiötz } & \multicolumn{2}{c}{ Applanation } \\
\cline { 2 - 6 } & & Mean & S.D. & Mean & S.D. \\
\hline \multirow{2}{*}{ Male } & Right & 14.6 & 2.96 & 15.9 & 3.04 \\
& Left & 14.6 & 2.96 & 15.9 & 2.87 \\
\hline \multirow{2}{*}{ Female } & Right & 15.6 & 2.84 & 16.6 & 2.97 \\
& Left & 15.7 & 2.87 & 16.6 & 2.88 \\
\hline
\end{tabular}

The upper limit of normal pressure is always asked for and has been falling steadily as more interest in the early detection of glaucoma has been aroused.

Statistical prediction of the probability of normality is only possible when the distribution of pressure in clinically normal persons is clearly defined and follows a form in which probabilities can be calculated. Two standard deviations above the mean in a Gaussian distribution encompass $97 \frac{1}{2}$ per cent. of all measurements.

Thus, readings higher than $21 \mathrm{~mm}$. $\mathrm{Hg}$ applanation have only a 2.5 per cent. probability of belonging to a normal distribution. This, of course, should not be construed as meaning clinical abnormality for the distribution is skewed and physiological variables need not necessarily follow a Gaussian distribution.

It has been claimed especially by Leydhecker (1964) that tonometric study of an overtly healthy population divides such a population into two groups according to whether their pressure readings fall within or without a statistically normal distribution. It is further claimed that such a statistical demarcation also separates physiological pressures from pathological pressures. Such a view implies a discontinuity between tonometric health and tonometric disease, and lends an air of urgency to mass tonometric screening programmes. In our results there is evidence only of a continuum of tonometric data and the dividing line between health and disease is difficult to place according to tonometric data alone. Davanger and Holter (1965) have produced theoretical evidence that supports the view that intraocular pressure distribution in normal persons could be skewed.

The remarks of Pickering (1955) regarding arterial pressure seem relevant to intra-ocular pressure: "The problems considered . . . have been bedevilled by the concepts normal and abnormal, healthy and unhealthy, physiological and pathological, into which categories it has long been the practice to try and force all phenomena that affect the well-being and expectation of life of man. These terms are 
essentially relative and insistence on their use, may in this as in other instances obscure the facts and prejudice the issues."

An upper level of normality cannot be derived from tonometric statistics alone, but must be based on other observations.

\section{THE GLAUCOMAS}

A. Definitions.-For our work we have defined the glaucomas as follows:

(1) Chronic Simple Glaucoma

A person was considered to be suffering from chronic simple glaucoma when he had in one or both eyes coincidence of:

(a) Glaucomatous cupping of the optic disc.

(b) Visual field defects of the following types: (i) Seidel; (ii) Bjerrum; (iii) Roenne's nasal step; (iv) Tubular.

(c) Pressure above or equal to, or known to have been above or equal to, $21 \mathrm{~mm}$. $\mathrm{Hg}$.

(d) An anterior chamber angle free of abnormal mesoderm and unobstructed by the root of the iris.

We feel that the diagnosis of chronic simple glaucoma is often loosely applied. The definition we use has the consent of tradition and its strict application would prevent additional confusion in the already chaotic literature of glaucoma epidemiology.

(2) Low Tension Glaucoma

(a) Suspected Low Tension Glaucoma was said to exist when a person had in one or both eyes coincidence of $1(a)(b)+(d)$ but whose pressure on first examination was less than $21 \mathrm{~mm}$. Hg with both Goldmann and Schiötz tonometry in the eye or eyes concerned.

(b) Low Tension Glaucoma-Confirmed.-As in 2 (a) above, but in addition subsequent pressure readings did not equal or exceed $21 \mathrm{~mm}$. $\mathrm{Hg}$ on any occasion.

(c) Low Tension Glaucoma-Unconfirmed.-As in 2 (a) above, but whose subsequent pressures in the affected eye exceeded or equalled $21 \mathrm{~mm}$. $\mathrm{Hg}$ on any occasion.

(3) Angle-Closure Glaucoma.-This was said to exist when a person had in the same or both eyes $(a)$ pressure $\geq 21 \mathrm{~mm}$. Hg by one or both methods, and $(b)$ an anterior chamber angle two-thirds obstructed, or known to have been so, by the root of the iris.

(4) Secondary Glaucoma.-This was said to exist when the pressure in one or both eyes was higher than or equal to $21 \mathrm{~mm}$. $\mathrm{Hg}$ with one or both methods, and was accompanied by an ocular lesion that could reasonably be assumed to have caused the raised pressure.

(5) Congenital Glaucoma.-This was said to exist when a pressure equal to or greater than $21 \mathrm{~mm}$. $\mathrm{Hg}$ was coincident with congenital abnormalities of the anterior chamber angle. 


\section{B. Prevalence of the Glaucomas}

(1) Chronic Simple Glaucoma occurred in thirteen persons (Table III)-that is, a prevalence rate of 0.28 per cent. Of these six were known and seven were discovered during our survey.

TABLE III

Glaucoma Prevalence

\begin{tabular}{l|c|c|c}
\hline \multicolumn{1}{c|}{ Type of Glaucoma } & No. of Cases & $\begin{array}{c}\text { Prevalence } \\
\text { (per cent. }\end{array}$ & Remarks \\
\hline $\begin{array}{l}\text { 1. Chronic simple } \\
\text { 2. Suspected low tension }\end{array}$ & 13 & $\begin{array}{l}0.28 \\
0.15\end{array}$ & $\left\{\begin{array}{l}6 \text { known } \\
7 \text { detected } \\
\text { All detected }\end{array}\right.$ \\
\cline { 2 - 4 } & 7 & 0.43 & - \\
\hline 3. Angle-closure & 20 & 0.09 & $\left\{\begin{array}{l}1 \text { known } \\
3 \text { detected } \\
\text { All known } \\
\text { 4. Congenital }\end{array}\right.$ \\
5. Secondary & 4 & 0.06 & $\begin{array}{l}10 \text { known } \\
2 \text { detected }\end{array}$ \\
\hline Grand Total & 12 & 0.26 & $\left\{\begin{array}{l}20 \text { known } \\
19 \text { detected }\end{array}\right.$ \\
\hline
\end{tabular}

(2) Low Tension Glaucoma was suspected in seven persons on initial examination (Table III). In three of these persons it was confirmed, in two chronic simple glaucoma was subsequently diagnosed, and the remaining two have not returned for further examination*.

If these seven persons are added to the thirteen chronic simple glaucomas, the prevalence rate is 0.43 per cent. This is of course much lower than most other workers' figures, but very similar to that reported by Strömberg (1962).

The age and sex of persons with chronic simple glaucoma and low tension glaucoma is shown in Table IV. Although the number of persons (20) with chronic simple glaucoma and suspected low tension glaucoma was small a definite increase in prevalence with age is evident.

There seems to be no significant sex difference in the prevalence of chronic simple glaucoma and low tension glaucoma.

TABLE IV

Chronic Simple and Low Tension Glaucoma

\begin{tabular}{c|c|c}
\hline \multirow{2}{*}{$\begin{array}{c}\text { Age Group } \\
\text { (yrs) }\end{array}$} & \multicolumn{2}{|c}{ Sex } \\
\cline { 2 - 3 } & Male & Female \\
\hline $40-44$ & - & - \\
$45-49$ & - & $\overline{2}$ \\
$50-54$ & $\overline{4}$ & 2 \\
$55-59$ & 4 & 3 \\
$60-64$ & $\overline{3}$ & 2 \\
$65-69$ & 2 & 2 \\
$70-74$ & 9 & 11 \\
\hline Total & 9 \\
\hline
\end{tabular}

The number of persons who were low tension glaucoma suspects was surprising to us and is very significant in relation to the value of tonometric screening, but it may be that the intractable nature of low tension glaucoma renders its detection of little consequence. In our population only about 30 per cent. of persons with glaucomatous field-loss were under medical care.

* Since this paper was submitted one of these two has been re-examined and shown to have occasional pressures up to $29 \mathrm{~mm}$. Hg (applanation). 
(3) Angle-Closure Glaucoma (Table III) was much less common, with a prevalence rate of 0.09 per cent. Newcomers are impressed by the low incidence of angleclosure glaucoma in South Wales. Three of the four cases were detected by the survey team.

(4) Congenital Glaucoma was diagnosed in three cases (Table III), 0.06 per cent. of the population.

(5) Secondary Glaucoma occurred in twelve persons, 0.26 per cent. of the population. Most were under medical care (Table III).

Our overall prevalence rate for glaucoma of all types was therefore 0.84 per cent. This seems a very low rate but it is what we found. There are two comments that we feel should be made regarding these figures: $(a)$ We suspect that most of the high rates of glaucoma prevalence that are quoted are falsely inflated by failure to distinguish clearly between established glaucoma and glaucoma suspects. (b) Until this work is repeated elsewhere on a similarly defined population and refuted or substantiated we see no reason why this prevalence rate should not be regarded as reliable.

\section{CHRONIC SIMPLE GLAUCOMA SUSPECTS}

These fall into three categories: (1) Ocular hypertension. (2) Enlarged optic cups. (3) Pseudo-exfoliation of the lens capsule.

\section{(1) Ocular HyPertensives}

\section{A. Definitions}

(1) Suspected Ocular Hypertension.-This was considered to be present when:

(a) The intra-ocular pressure was equal to or greater than $21 \mathrm{~mm}$. $\mathrm{Hg}$ in one or both eyes by indentation and/or applanation tonometry.

(b) There were no glaucomatous field defects.

(c) The anterior chamber angle of the eye or eyes that had a pressure $\geq 21 \mathrm{~mm}$. $\mathrm{Hg}$ was free of abnormal mesoderm.

(d) There was no history suggestive of, or of suffering from, angle-closure attacks.

(2) Unconfirmed Ocular Hypertensives.-Those who, although qualifying according to (1) above, on subsequent applanation tonometry, proved not to have a mean of three readings greater than or equal to $21 \mathrm{~mm}$. $\mathrm{Hg}$ in one or both eyes.

(3) Confirmed Ocular Hypertensives. - Those who qualified for (1) above and whose subsequent mean of three applanation pressures in one or both eyes was greater than or equal to $21 \mathrm{~mm}$. $\mathrm{Hg}$. We recommend the term "ocular hypertension" to other workers. As defined above it clarifies certain aspects of suspected glaucoma.

\section{B. Prevalence of Ocular Hypertension}

There were 397 suspected ocular hypertensives in the sample studied, that is, 8.61 per cent. of the total population. Of these 350 were subjected to an examination which included visual acuity, visual field examination, multiple tonometry, tonography, gonioscopy, retinoscopy, fundoscopy, and optic disc photography, and 93 
of them proved to be unconfirmed ocular hypertensives; 6.8 per cent. of the total population were confirmed ocular hypertensives.

\section{Age and Sex of Ocular Hypertensives}

There were relatively more women than men and the proportion of suspected ocular hypertensives increased with age, as can be seen in Fig. 9 and Table V. Over the age of 60 years suspected ocular hypertensives form more than 10 per cent. of the total population.

\section{TABLE V}

Age and Sex Incidence of Ocular Hypertensives (i.e. with intra-ocular pressure $21 \mathrm{~mm}$. $\mathrm{Hg}$ and above)

\begin{tabular}{c|c|c|c|c}
\hline \multirow{2}{*}{$\begin{array}{c}\text { Age Group } \\
\text { (yrs) }\end{array}$} & \multicolumn{2}{|c|}{ Males } & \multicolumn{2}{c}{ Females } \\
\cline { 2 - 4 } & No. of Cases & Per cent. & No. of Cases & Per cent. \\
\hline $40-44$ & 20 & $5 \cdot 8$ & 17 & $4 \cdot 6$ \\
$45-49$ & 22 & $7 \cdot 2$ & 33 & $10 \cdot 8$ \\
$50-54$ & 25 & $7 \cdot 2$ & 40 & $13 \cdot 4$ \\
$55-59$ & 20 & $6 \cdot 6$ & 45 & $15 \cdot 6$ \\
$60-64$ & 25 & $8 \cdot 8$ & 50 & $12 \cdot 0$ \\
$65-69$ & 20 & $10 \cdot 4$ & 30 & $18 \cdot 6$ \\
$70-74$ & 15 & $11 \cdot 8$ & 35 & \\
\hline Total & $147^{*}$ & & $250^{*}$ & \\
\hline
\end{tabular}

* Grand Total $=397(8.61$ per cent. of patients examined $)$

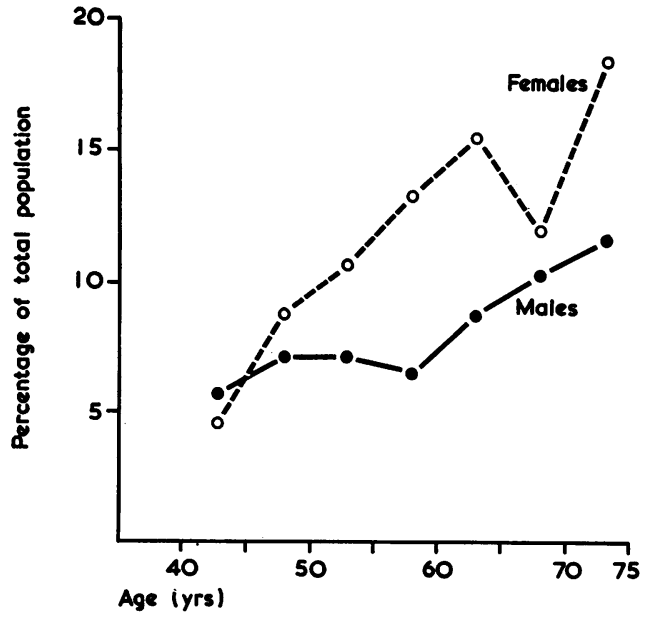

FIG. 9.-Distribution of 397 suspected cases of ocular hypertension (intra-ocular pressure $\geq 21 \mathrm{~mm}$. $\mathrm{Hg}$ ), by age and sex.

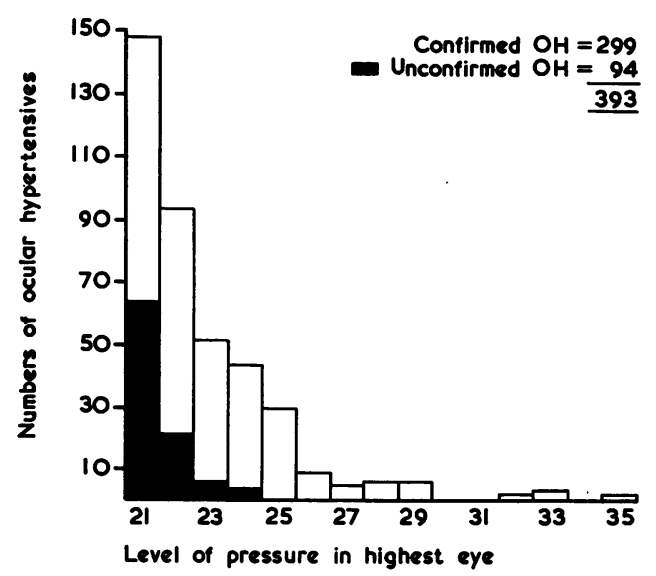

FIG. 10.-Level of pressure in higher eye in 393 ocular hypertensives.

\section{Pressure Attributes of $\mathbf{3 9 3}$ Ocular Hypertensives}

(1) These were distributed by pressure shown in Fig. 10. All persons with pressures higher than $24 \mathrm{~mm}$. Hg were confirmed; 14 per cent. of the ocular hypertensives had pressures equal to or greater than $25 \mathrm{~mm}$. $\mathrm{Hg}$. 
(2) An increased difference in pressure level between the two eyes is thought to be typical of ocular hypertensives and to increase suspicion of glaucoma. We have examined this right-left difference factor in relation to a group of normotensive and hypertensive subjects from the original survey sample.

In Fig. 11 right-left difference in applanation pressure is plotted for males against the pressure level in the right eye recorded by Observer 2. It shows that for both high and low pressures there is a greater right-left difference than that found at pressures close to the mean value. This is a "regression effect" and it occurs whenever data are treated in this manner. It simply means that the higher the pressure in one eye the more likely it is that the pressure in the other eye will be lower. We see no reason why a large right-left difference should have any more prognostic value than the level of pressure in the higher eye.

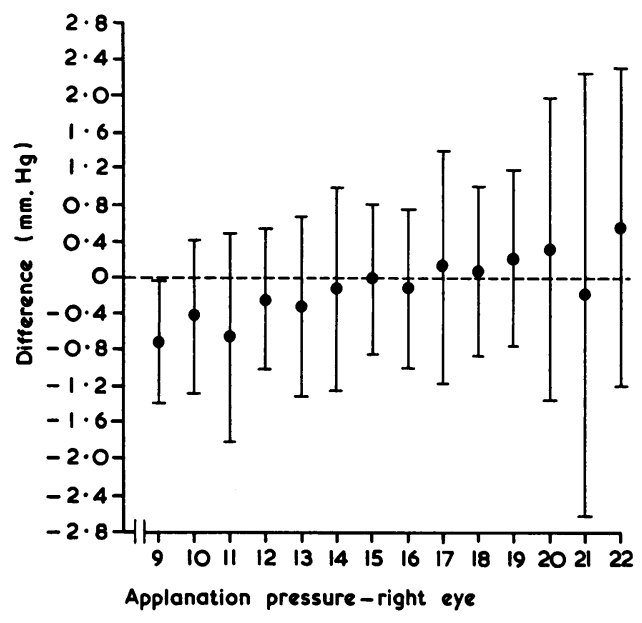

Fig. 11.-Differences in applanation pressure between right and left eye in male hypertension suspects.

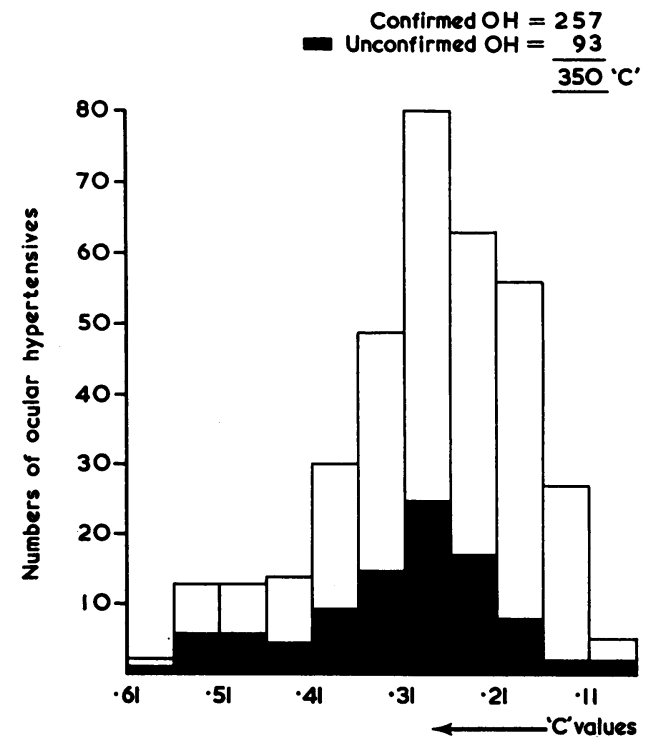

FIG. 12.-Facility of aqueous outflow ("C") in 350 ocular hypertensives.

\section{E. Tonographic Attributes of Ocular Hypertensives}

Measurement of facility of aqueous outflow (C) is widely thought to separate the ocular hypertensive sheep from the preglaucomatous goats. 350 ocular hypertensives were distributed according to "C" as shown in Fig. 12; 47 were not measured for various reasons.

Of the remaining 350 , seven ( 2 per cent.) had " $\mathrm{C}$ " values of $0 \cdot 11$ or less; forty (11 per cent.) had values of 0.16 or less; and 106 (30 per cent.) of 0.21 or below. Means and standard deviations for $\mathrm{C}$ values for 114 male right eyes are shown in Fig. 13 (overleaf); " $\mathrm{C}$ " decreases with age and this decrease is more marked after 60 years. Male left eyes and both female eyes have similar " $C$ " values.

The ratio $\frac{\text { intra-ocular pressure }}{\text { facility of outflow }}(\mathrm{Po} / \mathrm{C})$ is thought further to separate ocular hypertensives as regards prognosis. Our ocular hypertensives were distributed according 


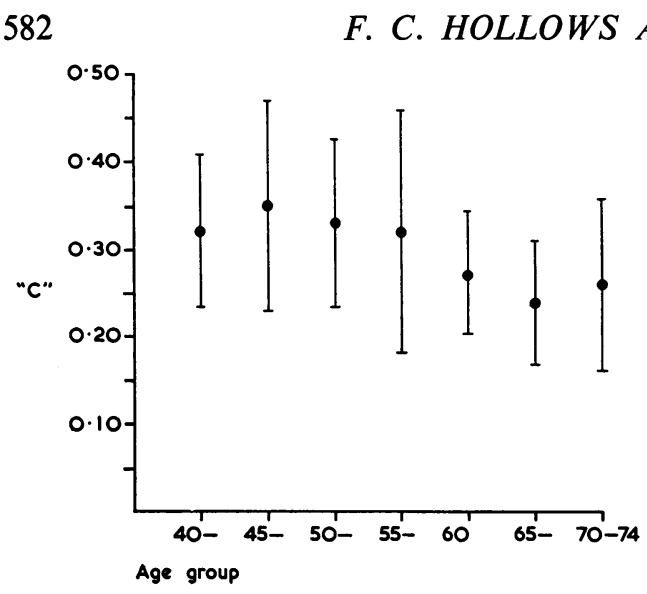

FIG. 13.-Means and standard deviations for " $C$ " values in 114 male right eyes, by age group.

to this parameter as shown in Fig. 14; five persons $(1.4$ per cent.) were higher than 200 , and 83 (25 per cent.) were equal to or higher than 100 .

Mean $\mathrm{Po} / \mathrm{C}$ increases with age as is shown in Fig. 15. The ratio has a large standard deviation and again there is a tendency for this to change at 60 years.

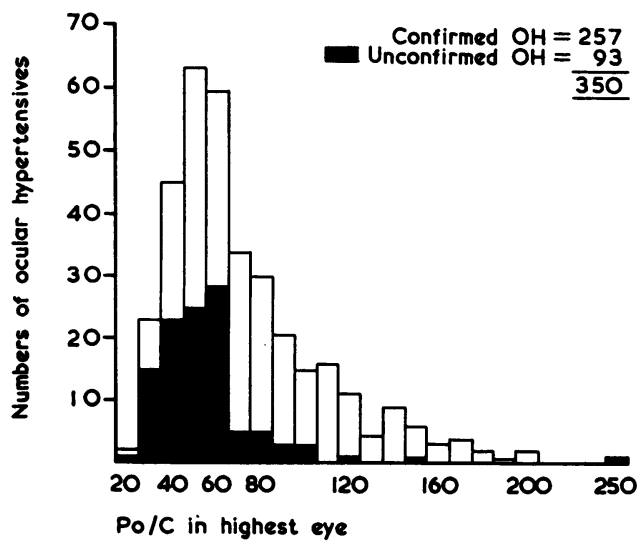

FIG. 14.-Ratio of intra-ocular pressure $P_{0}$ to " $C$ " in higher eye in 350 ocular hypertensives.

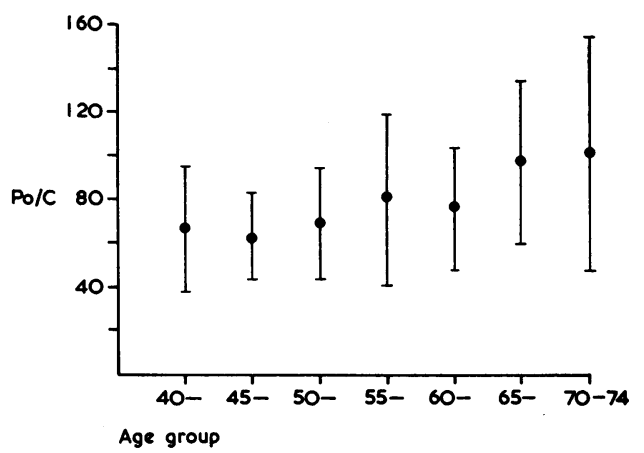

Fig. 15.-Mean and standard deviation for $\mathrm{P}_{\mathrm{o}} / \mathrm{C}$ ratio in 114 male right eyes, by age group.

\section{F. Optic Disc Attributes of Ocular Hypertensives}

Increased intra-ocular pressure in some cases may lead to excessive excavation of the optic disc. We have developed and statistically evaluated a graticule method of gauging from standardized optic disc photographs the proportion of the disc involved in the excavation (Fig. 16). (Full details of this method will be published later.)

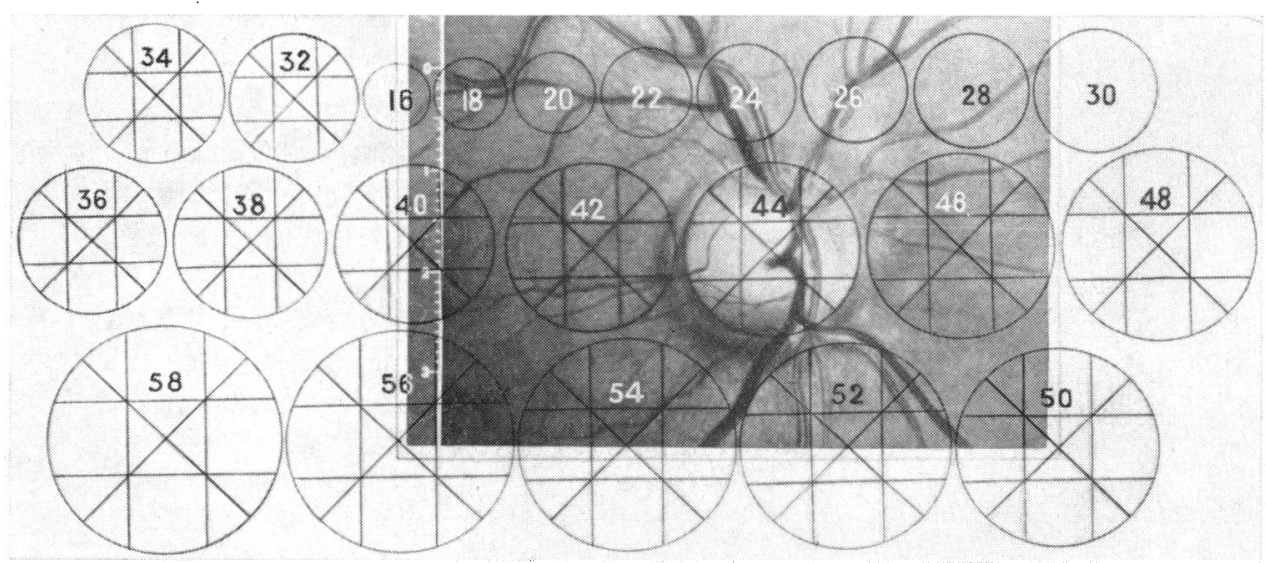

FIG. 16.-Graticule for measuring optic disc and cup in use. 
Using this method we have compared the disc photographs of half the suspected ocular hypertensives randomly selected from within the ocular hypertensive sample with half of the number of persons (randomly selected) who on examination during the survey had ocular pressures at or below $13 \mathrm{~mm}$. $\mathrm{Hg}$ applanation.

The ocular hypertensives do not have either more or less excavation of the optic disc than have the low pressure group. Therefore as regards size of optic cup we find ocular hypertensives indistinguishable from non-ocular hypertensive persons.

\section{G. Actuarial Aspects of the Relationship between Ocular Hypertension, Low Outflow} Facility, and Chronic Simple Glaucoma

From our figures of the prevalence of ocular hypertension, $\mathrm{Po} / \mathrm{C}$ greater than or equal to 100 , and chronic simple glaucoma, our statisticians calculated rates per 1,000 per year for a population aged between 40 and 75 years. This information is shown graphically in Fig. 17. Assuming that the mortality rates for persons with ocular hypertension, raised $\mathrm{Po} / \mathrm{C}$, and chronic simple glaucoma do not differ from normal, quantitative estimates in terms of person-years for each of these states have been derived.

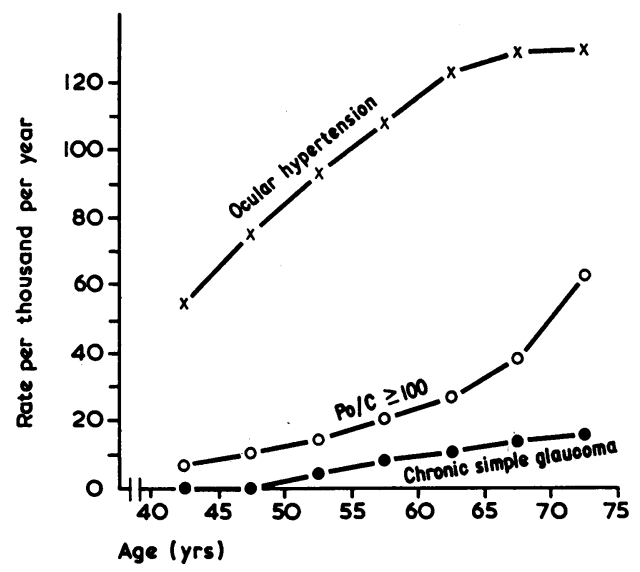

FIG. 17.-Estimated rates per 1,000 per year of cases of ocular hypertension, high $\mathrm{P}_{\mathrm{o}} / \mathrm{C}$ ratio, and chronic simple glaucoma, by age.

Of 1,000 persons aged 40 , a total of 29,310 years will be lived by the time the survivors are 75 years old. From our prevalence figures there would be (Table VI)

TABLE VI

Relative Proportions of "Person-Years" in Population of "Raised" Pressure, Po/C Ratio $\geqslant 100$, and Chronic Simple Glaucoma

\begin{tabular}{c|c|c|c|c|c}
\hline $\begin{array}{c}\text { Age Group } \\
\text { (yrs) }\end{array}$ & $\begin{array}{c}\text { Life } \\
\text { Table }\end{array}$ & $\begin{array}{c}\text { Years of } \\
\text { Life Lived }\end{array}$ & $\begin{array}{c}\text { Years of } \\
\text { Ocular } \\
\text { Hypertension }\end{array}$ & $\begin{array}{c}\text { Years of } \\
\mathbf{P}_{0} / \mathrm{C} \geq 100\end{array}$ & $\begin{array}{c}\text { Years of } \\
\text { Chronic Simple } \\
\text { Glaucoma }\end{array}$ \\
\hline $40-44$ & 1,000 & 4,960 & 273 & 30 & - \\
\hline $45-49$ & 983 & 4,805 & 360 & 48 & - \\
\hline $50-54$ & 958 & 4,700 & 432 & 56 & 14 \\
\hline $55-59$ & 921 & 4,460 & 476 & 85 & 27 \\
\hline $60-64$ & 864 & 4,110 & 497 & 120 & 37 \\
\hline $65-69$ & 780 & 3,575 & 454 & 148 & 39 \\
\hline $70-74$ & 650 & 2,700 & 346 & 162 & 35 \\
\hline Total Years Lived & & 29,310 & 2,838 & 649 & 152 \\
\hline Person-Years & & 176 & 17 & 4 & 1 \\
\hline
\end{tabular}


2,838 person-years of ocular hypertension, 649 person-years of raised $\mathrm{Po} / \mathrm{C}$, and 152 person-years of chronic simple glaucoma lived by the time the survivors of the 1,000 persons reached the age of 75 years.

Therefore there will be four times as many person-years of raised $\mathrm{Po} / \mathrm{C}$ as there will be chronic simple glaucoma person-years, and seventeen times more person-years of ocular hypertension than chronic simple glaucoma person-years.

These computations seem to cast doubt on the value of mass tonometric and tonographic screening of pre-symptomatic persons as the false positive rate is excessive.

Further implications of this actuarial analysis and other findings in relation to screening methods for glaucoma will be published elsewhere (Graham and Hollows, 1966).

\section{(2) Enlarged Optic Cups}

A. Definition.-Persons said to have enlarged optic cups when the ophthalmoscopist noted excessive excavation of one or both discs during the initial survey examination. Persons with such excessive excavation can be considered as glaucoma suspects.

\section{B. Prevalence, Age, Sex, and Classification of Persons with Enlarged Optic Cups}

(1) Prevalence.-We noted 102 persons with enlarged optic cups, or $2 \cdot 2$ per cent. of the total population.

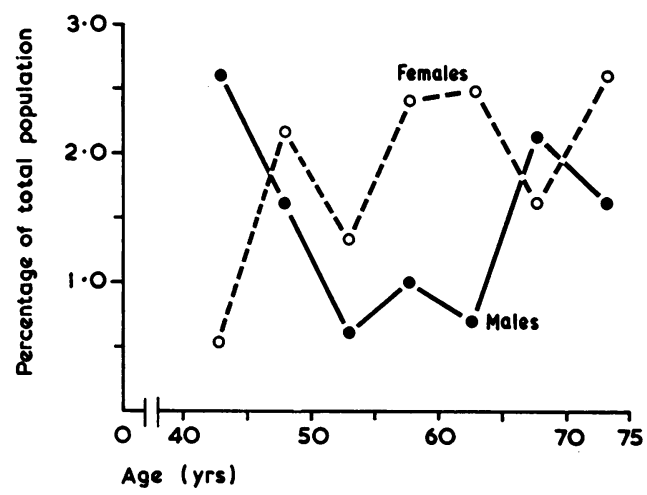

(2) Age and Sex.-Non-glaucomatous persons with enlarged optic cups were divided between the sexes and scattered amongst the different age groups without pattern (Fig. 18).

Fig. 18.-Prevalence of enlarged optic cups by age and sex.

(3) Classification.-Of the 102 persons, 89 who were re-examined fell into the following six groups as already defined:

i. Those who proved to have chronic simple glaucoma 13

ii. Those who had suspected low tension glaucoma $\quad 7$

iii. Those with congenital glaucoma 3

iv. Those with angle-closure glaucoma 1

v. Those with ocular hypertension 17

vi. Those with enlarged optic cups $\quad 48$ 
In our population 54 per cent. of all persons with enlarged optic cups had no other indication of glaucoma; 19 per cent. had ocular hypertension and 27 per cent. had some form of glaucoma.

\section{(3) Pseudo-Exfoliation of the Lens Capsule}

A. Definition.-Persons were said to have this condition when the characteristic white flakes were seen on the pupil rim or the lens capsule by the biomicroscopist.

\section{B. Prevalence and Classification}

There were ten such persons in our population, or 0.22 per cent. None had glaucoma but two had pressures higher than $21 \mathrm{~mm}$. $\mathrm{Hg}$ on both tonometers. A more searching examination of 1,023 members of the initial population when their pupils were dilated did not uncover any further cases.

\section{Conclusions}

Long-term follow-up studies of the three groups of glaucoma suspects are in progress. If the three groups of glaucoma suspects, as defined, are aggregated (counting persons who fall into more than one group once only) the prevalence rate is $9 \cdot 1$ per cent. The bulk of these are ocular hypertensives. Considerable facilities will be required if intensive aqueous dynamic studies and follow-up examinations are to be done in such a large proportion of the population. We feel that at present there is insufficient evidence for the efficiency of procedures that separate pre-glaucoma cases from glaucoma suspects for wholesale total population screening programmes to be undertaken. Much work needs to be done on the variations affecting aqueous dynamics in normal persons, and the relationship between "abnormal" aqueous outflow results and the development of glaucomatous visual loss, if glaucoma suspect analysis is to be efficient. A reliable, easily performed indicator of susceptibility of the optic disc to damage by ocular pressure is urgently needed.

Accurate prognostication of the clinical course in glaucoma suspects awaits the results of prospective long-term follow-up studies.

\section{Summary}

The aims and methods of a total population study of intra-ocular pressure, glaucoma, and glaucoma suspects are described.

Applanation pressure in non-glaucomatous persons is skewed to the high side of the mean. The distribution is affected by:
(1) Age
(2) Sex
(3) Time of day
(4) Digit preference
(5) Decision effect

Schiötz pressure distribution is distributed bimodally if low scale division readings 
are avoided by changing weights. This bimodality is an artefact. The distribution is affected by:

(1) Age in females but not in males

(2) Sex

(3) Time of day

The meaning of normal and average intra-ocular pressure is discussed and a plea made for the consideration of pressure variations from normal to abnormal as a continuum.

The glaucomas are defined.

The prevalence is given in the population studied of:

(1) Chronic simple glaucoma

(2) Low tension glaucoma

(3) Angle-closure glaucoma

(4) Congenital glaucoma

(5) Secondary glaucoma

The age and sex distribution of persons with chronic simple glaucoma and low tension glaucoma is given.

Chronic simple glaucoma suspects are defined and described in three groups:

(1) Ocular hypertensives

(2) Persons with enlarged optic cups

(3) Persons with pseudo-exfoliation of the lens capsules

Actuarial aspects of the relationship between ocular hypertension, tonographic abnormalities, and chronic simple glaucoma are described.

Prevalence rates for each group of glaucoma suspects are given. Comments are made on the present position of predicting the clinical fate of these suspects. The need for long-term prospective follow-up studies is stressed.

We wish to thank Prof. A. L. Cochrane and his team of workers for their untiring assistance, and Dr. Hubert Campbell and Mr. T. Khosla for their statistical assistance in planning, executing, and analysing the results of this survey. We are especially indebted to Dr. Morley Davies and the population of the Rhondda Fach for their friendly co-operation, and to the Ministry of Health for financial aid and sympathetic interest. To Mr. F. Moore and Mr. R. Marshall of Cardiff and Mr. K. Deason of Sydney, we are grateful for provision of the illustrations. For secretarial help in the preparation of this paper we thank Miss Irene Calford and Mrs. Maxine Mackenzie.

\section{REFERENCES}

Armaly, M. F. (1965). Arch. Ophthal. (Chicago), 73, 11.

Davanger, M., and Holter, O. (1965). Acta ophthal. (Kbh.), 43, 314.

Graham, P. A., and Hollows, F. C. (1964). Trans. ophthal. Soc. U.K., 84, 597. (1965). In "Glaucoma", ed. Hunt. Livingstone, Edinburgh.

LEYDHECKER, W. (1964). Personal communication.

Pickering, G. W. (1955). "High Blood Pressure", p. 183. Churchill, London.

StröMBERG, U. (1962). Acta ophthal. (Kbh.), Suppl. 69. 